\title{
Adaptive Learning Based on Affect Sensing
}

Citation for published version (APA):

Tsatsou, D., Pomazanskyi, A., Hortal, E., Spyrou, E., Leligou, H. C., Asteriadis, S., Vretos, N., \& Daras, P. (2018). Adaptive Learning Based on Affect Sensing. In R. C. Penstein (Ed.), Artificial Intelligence in Education. AlED 2018 (pp. 475-479). Springer, Cham. Lecture Notes in Computer Science Vol. 10948 https://doi.org/10.1007/978-3-319-93846-2_89

Document status and date:

Published: 01/01/2018

DOI:

10.1007/978-3-319-93846-2_89

Document Version:

Publisher's PDF, also known as Version of record

Document license:

Taverne

Please check the document version of this publication:

- A submitted manuscript is the version of the article upon submission and before peer-review. There can be important differences between the submitted version and the official published version of record.

People interested in the research are advised to contact the author for the final version of the publication, or visit the DOI to the publisher's website.

- The final author version and the galley proof are versions of the publication after peer review.

- The final published version features the final layout of the paper including the volume, issue and page numbers.

Link to publication

\footnotetext{
General rights Owners
rights.

- You may freely distribute the URL identifying the publication in the public portal. please follow below link for the End User Agreement:

www.umlib.nl/taverne-license

Take down policy

If you believe that this document breaches copyright please contact us at:

repository@maastrichtuniversity.nl

providing details and we will investigate your claim.
}

Copyright and moral rights for the publications made accessible in the public portal are retained by the authors and/or other copyright owners and it is a condition of accessing publications that users recognise and abide by the legal requirements associated with these

- Users may download and print one copy of any publication from the public portal for the purpose of private study or research.

- You may not further distribute the material or use it for any profit-making activity or commercial gain

If the publication is distributed under the terms of Article $25 \mathrm{fa}$ of the Dutch Copyright Act, indicated by the "Taverne" license above, 


\title{
Adaptive learning based on affect sensing
}

\author{
Dorothea Tsatsou ${ }^{1}$, Andrew Pomazanskyi ${ }^{2}$, Enrique Hortal ${ }^{3}$, Evaggelos \\ Spyrou $^{4}$, Helen C. Leligou ${ }^{5}$, Stylianos Asteriadis ${ }^{3}$, Nicholas Vretos ${ }^{1}$, and Petros \\ $\operatorname{Daras}^{1}$ \\ 1 Information Technologies Institute, Centre for Research \& Technology Hellas, \\ Thessaloniki, Greece, dorothea, vretos, daras@iti.gr \\ 2 Nurogames, Cologne, Germany, andrew.pomazanskyi@nurogames.com \\ 3 University of Maastricht, Maastricht, The Netherlands, enrique.hortal, \\ stelios.asteriadis@maastrichtuniversity.nl \\ 4 Institute of Informatics \& Telecommunications, National Centre for Scientific \\ Research "Demokritos", Athens, Greece, espyrou@iit.demokritos.gr \\ ${ }^{5}$ OTE Academy, Athens, Greece, leligou@gmail.com
}

\begin{abstract}
This paper introduces an end-to-end solution for dynamic adaptation of the learning experience for learners of different personal needs, based on their behavioural and affective reaction to the learning activities. Personal needs refer to what learner already know, what they need to learn, their intellectual and physical capacities and their learning styles.
\end{abstract}

\section{Introduction}

The emergence of new technologies has enabled the educational paradigm to shift from traditional classroom-based instruction to ubiquitous, highly personalised learning. Through the recognition of sensorial and performance cues, learning can adapt to each individual learner's preferences, situation and needs. Such cues may now be tracked seamlessly via the technological agents and digital content that materialise learning activities.

Moreover, the effectiveness of the learning process has been directly correlated with the learners' engagement to the learning activities [4], which increases when activities are tailored to the personal needs and emotional state of the learner [2]. As such, a major challenge is to provide personal mentors for learners and means for teachers' to amplify their awareness and progress monitoring capacities.

To this end, this paper outlines the novel ecosystem of the MaTHiSiS EU-funded project that pertains to an innovative modelling strategy for learning experiences, multimodal affect recognition over a variety of learner types (with and without disabilities) and an on-the-fly adaptation strategy of the learning experience, as seen in Figure 1 .

\section{Learning experience modeling}

A novel framework for modeling learning experiences has been developed, comprising of (a) a graph-based representation of the learning objectives (i.e. what to learn) and (b) a knowledge-based schema of the learning activities (i.e. what to do to learn). 


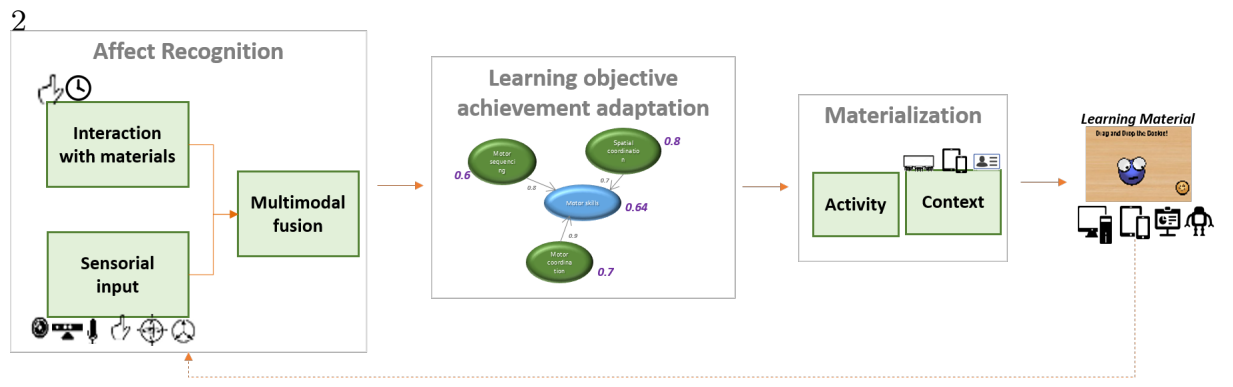

Fig. 1. The MaTHiSiS ecosystem's core workflow

The graph-based modeling scheme provides educators the means and method to define re-usable, self-sustained and interoperable learning objectives, discretised into smaller learning goals, which represent competences, skills, or knowledge that they aim for their learners to acquire. Goals are interconnected in directed learning graphs, with different contribution degree (edge weights). Complex goals comprise the central-most nodes and atomic goals comprise leaf nodes that contribute to one or more complex goals. These atoms are competences that cannot be further reduced to more primitive notions.

Generic learning activities are attached to the atomic goals, while different materialisations for each activity can be defined based on contextual conditions (device used etc.). A Learning Actions Ontology has been engineered, based on educators and psychologists feedback, to represented under a holistic schema such abstract activities, but also parameters that affect their materialisation in the real world, such as the type of learner, the types of devices used during a learning session, the types of digital content, etc. Further details on the learning experience modeling strategy can be found in 9 .

\section{Affect recognition during learning}

Achievement in a learning objective is maximised when the learner is engaged [4, i.e. when learner's skill and activity challenge levels are balanced comfortably and the learner feels neither frustrated nor bored.

The physical behaviour of a learner can be tracked through diverse sensing devices, such as cameras, microphones, gyroscopes, etc., and along with the learners' interactions with the digital content and devices they provide direct indications towards the learners' engagement, frustration and boredom.

In the case of the MaTHiSiS system, a key challenge was the different types of learners that it addresses, and subsequently the very diverse expressions of affect. Spanning from children to adults and from neurotypical learners to learners with learning and physical disabilities, both the unavailability of datasets, as well as the intricacies posed by the types of learners, mandated the creation of a new dataset, during extensive piloting phases. To this end, recordings of neurotypical children and adults, as well as children and teens in the autism spectrum and with multiple and profound disabilities, working on educational material (on desktop, mobile devices and in certain cases with an educational 
robot ${ }^{6}$ were annotated by their teachers and pedagogical experts-observers with affect state labels, in order to train machine learning algorithms for a multitude of modalities, outlined below.

Facial expression analysis: The graph-based method presented in [1] exploits the variation of interconnected facial landmark positions, to predict leaner affect per certain timeframes.

Gaze estimation: A two-stream CNN method has been developed, fusing the spatial stream of the eye pupil with the temporal stream of the pupil's optical flow in a particular timeframe, in a 3D gaze vector. Based on gaze - affect label correlations in the dataset, the affect state of the learner is estimated.

Skeleton Motion Analysis: Through Slow Feature Analysis and Speed Relation Preserving Slow Feature Analysis (srpSFA), the geometrical structure of the moving skeletons of a learner is leveraged in order to extract features that capture the affective context of an action.

Speech-based affect recognition: Audio signals are transformed to a sequence of feature vectors, classified through SVMs, based again on the labelled dataset. Experiments have indicated that this method may be language-independent 7 . Inertial sensor-based affect recognition: An affect recognition system which exploits the expression through 2D and 3D gesture using the accelerometer and gyroscope has been developed. These 2D but especially 3D descriptors contribute to emotion expression while interacting and using mobile devices.

Interaction with learning material: the Experience API (xAPI) [5 has been extended, in order to express prominent interactions of learners with educational materials, where time to complete a task, potential score, and type of interaction are employed in order to recognise behavioural affective cues of the learner.

All these channels are fused under an equally-weighted late multimodal fusion scheme, to result to an understanding of the overall affect of the learner at any given moment of the learning experience, since multi-channel fusion of affect states has already been proven to improve accuracy and reduce discrepancy in the recognition of affective states, in comparison to single-channel recognition 3 .

\section{Personalised adaptation of the learning experience}

While each teacher-defined learning graph applies to all learners, personalised instances of the graphs are assigned to each user, on which weights over the graph's nodes reflect each learner's achievement (or skill) level over each goal. This goal-oriented framework enables nonlinear training over the overall learning objective, as the system will promote learning activities, and level of challenge thereof, that train goals where the learner is weakest at, during each iteration of the learning experience.

Adaptation of the learning process relies on two axes: (a) the affect state of the learner while they are training in a specific atomic learning goal and (b) the learning graph structure and state of the personal graph instance in each iteration of the learning process. Content recommendation and learning process intervention based on student's affect has been pursued in [8] and [6] respectively, however not as means to fully guide the learning process itself or in direct

\footnotetext{
$6 \longdiv { \text { NAO robot } }$
} 
combination with the learning experience model.

For the first part, once the affect of a learner is detected to be out of the flow state, the system automatically adjusts the skill level of the learner (atomic goal weight). If the affect state tends to boredom, the skill level is increased, so that the challenge level would ultimately be increased. In the case of anxiety detection, the skill is lowered, so that the challenge for the activities of this particular goal will be subsequently relaxed.

For the second step, graph-based update of the learning graph instance analyses the current goal weight change and previous state of the graph instance and (re)adapts all goals' weights, so that it reflects both (i) the contribution of the goals to the overall learning objective and (b) a smooth transition in knowledge acquisition. The latter ensures that there are no potential steep oscillations of goal weights from the previous adaptation step due to circumstantial conditions and that goal achievement score reflects the true progression of the learner.

Lastly, the generic learning activity selected based on the aforementioned 'weakest link' selection criterion is matched against the contextual situation of the learner (abilities, environment, device used) to result to the current appropriate materialisation of the activity.

Preliminary piloting observations have indicated the effectiveness of the platform towards (a) maintaining neurotypical and non-neurotypical learners engaged so that they retain their focus in the material they learn and (b) befittingly adapting the material (e.g. exercise/game) challenge level according to the learners' affect state, so that they are comfortable with the exercises taken up, thus successfully fulfilling them, with a direct correlation to increasing skill levels, while at the same time learners do not remain complacent about past achievements but are rather motivated to take up new/more skills.

\section{Conclusions and Future Work}

This paper presented the MaTHiSiS educational ecosystem and its main innovation arches, i.e. the novel learning experience modeling paradigm for learners with and without learning and physical disabilities, as well as the holistic affectbased adaptation of the learning process.

The system has been tested in extensive pilots with the core strengths and opportunities of the proposed solution brought to light. To this end, the personal mentoring capacities of the system, its applicability to any setting and device, the ability for teachers to re-use the learning experience model components and to monitor their students' progress and affect state, but most prominently its ability to maintain learners with or without disabilities engaged with the learning process are of the major strengths and innovation potentials of the platform. Future work will focus on enforcing a reliability factor during multimodal fusion to each affect recognition modality based on the type of learner.

\section{Acknowledgments}

This work has been supported by the European Commission under Grant Agreement No. 687772 MaTHiSiS. 


\section{References}

1. Antonaras, D., Pavlidis, C., Vretos, N., Daras, P.: Affect state recognition for adaptive human robot interaction in learning environments. In: Semantic and Social Media Adaptation and Personalization (SMAP), 2017 12th International Workshop on. pp. 71-75 (2017)

2. Athanasiadis, C., Hortal, E., Koutsoukos, D., Lens, C.Z., Asteriadis, S.: Personalized, affect and performance-driven computer-based learning. In: Proceedings of the 9th International Conference on Computer Supported Education - Volume 1: CSEDU, (2017)

3. DMello, S.K., Graesser, A.: Multimodal semi-automated affect detection from conversational cues, gross body language, and facial features. User Modeling and UserAdapted Interaction 20(2), 147-187 (2010)

4. Hamari, J., Shernoff, D.J., Rowe, E., Coller, B., Asbell-Clarke, J., Edwards, T.: Challenging games help students learn: An empirical study on engagement, flow and immersion in game-based learning. Computers in Human Behavior (2016)

5. Kevan, J.M., Ryan, P.R.: Experience api: Flexible, decentralized and activity-centric data collection. Technology, knowledge and learning (2016)

6. Mazziotti, C., Holmes, W., Wiedmann, M., Loibl, K., Rummel, N., Mavrikis, M., Hansen, A., Grawemeyer, B.: Robust student knowledge: Adapting to individual student needs as they explore the concepts and practice the procedures of fractions. In: Workshop on Intelligent Support in Exploratory and Open-Ended Learning Environments Learning Analytics for Project Based and Experiential Learning Scenarios at the 17th International Conference on Artificial Intelligence in Education (AIED 2015). pp. 32-40 (2015)

7. Papakostas, M., Spyrou, E., Giannakopoulos, T., Siantikos, G., Sgouropoulos, D., Mylonas, P., Makedon, F.: Deep visual attributes vs. hand-crafted audio features on multidomain speech emotion recognition. Computation (2017)

8. Santos, O.C., Saneiro, M., Salmeron-Majadas, S., Boticario, J.G.: A methodological approach to eliciting affective educational recommendations. In: Advanced Learning Technologies (ICALT), 2014 IEEE 14th International Conference on. pp. 529-533. IEEE (2014)

9. Tsatsou, D., Vretos, N., Daras, P.: Modelling learning experiences in adaptive multiagent learning environments. 2017 9th International Conference on Virtual Worlds and Games for Serious Applications (VS-Games) pp. 193-200 (2017) 